\title{
THE DRONES AND ISSUES CONNECTED WITH THEIR USE IN CONTEMPORARY CONFLICTS
}

\author{
Richard STOJAR \\ University of Defence, Brno, The Czech Republic \\ richard.stojar@unob.cz
}

\begin{abstract}
The text deals with the development and methods of use of Drones or Unmanned Aerial Vehicles in contemporary conflicts or special operations. The contribution tries to present the main advantages of these vehicles as being the main reasons for their current use in armed forces of state as well as non-state actors and their dynamic proliferation in global space in past years. We can observe a new trend in the armed conflict in the last two decades - use of advanced systems of unmanned vehicles in such a range that many military and academic experts talk about a new wave of revolutionary changes in the military affairs. This wave, or we could even talk about militarytechnological breakthrough should lead to imminent use of these systems in contemporary as well as future conflicts which would result in the partial or complex robotization of the battlefield. Specific attention is dedicated to controversies tied to the use of Drones/Unmanned Aerial Vehicles in socalled Drone Warfare and current discussion in the context of cultural or societal dimension of their use and perspectives for further development.
\end{abstract}

\section{Keywords: Drones, Unmanned Aerial Vehicles, contemporary conflicts, robotization}

\section{Introduction}

In the last two decades, it is possible to observe a new significant trend in armed conflicts, consisting in the deployment of advanced remotely controlled reconnaissance and weapon systems, to such an extent that some military and academic experts speak of a new wave of revolutionary changes in the military field. This wave or even the militarytechnological breakthrough can lead to an increased use of such systems in contemporary and future conflicts and result in either partial or full robotization of the battlefield. The deployment of unmanned systems is not a surprising novelty, and their use corresponding to the respective technical possibilities can be traced back to the second half of the $20^{\text {th }}$ century, however, technological progress has also occurred in this field, allowing unprecedented development. In the case of the contemporary resources we can really talk about at least a partial militarytechnological revolution, as it is defined at the expert level, based on the substantial shift in their capacities [1].

\section{Evolution}

In the last 15 years, global attention was directed in particular to the strikes of armed UAVs implemented by the CIA against terrorist and insurgent groups in the Near and Middle East as well as the dynamic proliferation of reconnaissance drones in the armed forces of a number of states and also non-state actors. There is a clear general trend toward intensification of the UAVs and their utilization for air strikes. The first actual deployment of the UAVs 
for reconnaissance and observation activities can be dated to the period of the Vietnam War, where American troops, faced with an increasing air defence of the adversary, started to use reconnaissance drones, thus eliminating the potential losses of human crews in high risk missions. Despite the positive experience, in the 1970 s this program was not further developed in the US, however, several drones of this type were received by Israel as part of the military aid. In the following decades this country became their principal innovator and practical user in combat deployment. After the experience of Yom Kippur War of 1973, when the Israeli army faced strong air defence of the Arab states, Israel sought an efficient tool for its elimination. In the conflict with Syria of 1982, the Israeli side fairly robustly used reconnaissance drones for the detection and subsequent inefficient activation of the adversary's air defence weapons. The positive Israeli experience with the unmanned aerial systems attracted the attention in the US, arousing a revival of interest in these technologies. The United States subsequently started the development of a new generation of drones, and their first operational deployment occurred already during the Gulf War in 1991 [2]. This demonstrated not only their effectiveness in reconnaissance tasks but also the psychological impact they had on the Iraqi opponent. In 1995, the first drone of the Predator type was produced in the US, which was, despite its name, intended only for exploratory purposes. It was first directly put into service in 1999 during the so called Kosovo crisis, to perform reconnaissance tasks and mark targets to be subsequently attacked by piloted combat aircrafts. At that time, Yugoslavia became an area of so far unprecedented deployment of several types of reconnaissance drones by the alliance states. The analysis of the use of drones revealed their extensive potential, albeit with certain downsides. The machines that were used, for example, identified large quantities of false targets, and several of the drones were eliminated by the Yugoslav air defence. The overall usefulness of the concept, however, was confirmed also here, and further positive experience was soon obtained with deploying drones in Afghanistan after 2001. Still based on the experience from Kosovo, in an experiment, the Predator drone was armed with the Hellfire anti-tank guided missile, the first tests starting in February 2001. The US operations in Afghanistan then allowed an unusually quick transition from the experiment to the practical application in combat. With the military involvement of the US in Afghanistan and Iraq, there was a real boom of drones, both reconnaissance and armed ones, leading to further major development in this area. Former CIA director L. Panetta described the program of targeted liquidation using armed drones as the only measure that is able to fight al-Qaeda effectively on a global scale [3]. The increase in the numbers of unmanned military aircrafts in the US was demonstrated also by the fact that in 2010 their number was 40 times higher compared to 2002 [4]. The economic dimension of the introduction of drones among the weaponry is also significant nowadays. In addition to the low cost compared to the use of piloted fighter jets in the operations there is a significant comparative advantage in the acquisition process. For the price of one military airplane of the fifth generation F-35, now introduced in the western armed forces, at present it is possible to acquire a multifunction system with approximately 10-12 multifunction drones including the complete associated logistical equipment, while the probability of operational deployment is now even greater than it is in the case of a piloted machine.

A relatively specific category of armed unmanned aircrafts is currently represented by the self-destructive units, so called kamikaze drones. These drones are a product of the partial improvisation and 
they are not such sophisticated systems as the American types Predator or Reaper, but for many users they are more accessible, even though they are intended only for a one time use. The deployment of these machines in combat was seen in the case of the short-term escalation of the conflict in Nagorno-Karabakh. In April 2016, Azerbaijani forces utilized a modified Israeli drone of the Harop type in the attack on the Armenian military convoy. A similar use took place in early October 2016 by the Islamic State in the attack on the base near Erbil in Iraqi Kurdistan. These recorded incidents can be assessed from the perspective of the user as successful, as the drones caused significant human casualties among the enemy with a small cost in comparison to the conventional weapons. In the case of the Islamic State, the drone used was probably only an inexpensive civilian commercial model equipped with an explosive charge, which confirms the anticipated trend of exploiting these accessible resources for asymmetric forms of struggle and terrorist attacks.

\section{Perspectives}

The prospective utilization of drones in the future, however, includes a far greater range of military activities than it is the case today. Because of the reduced physical capacities of a human organism, full and complete replacement of piloted fighter aircrafts by unmanned air systems can be expected in the future. A trained human can withstand a maximum load of $8 \mathrm{G}$, whereas a drone has no such restrictions and its design does not need to take account of additional needs or limits of the human crew [5]. The future of air battles and achieving dominance in the air will probably also become a domain of machines from which the human element will be completely absent. In this respect, some countries have already declared initiating their own program of development of unmanned supersonic or hypersonic combat airplanes of the future.
The Russian Federation, for instance, presented an ambitious project of developing hypersonic multi-functional fighter drones of the sixth generation, with the first flight expected in 2025. The deployment of these resources should be the mix of one to two piloted machines, the operators of which would coordinate the action of 5 to 10 unit swarms using the elements of swarming tactics. Similar intention was declared previously by the US Navy, planning prospectively to replace the F-35, still not in service, by currently tested unmanned supersonic units [6].

Currently, there is a specific advantage in the use of armed drones by the US side for targeted liquidation of enemy individuals, which may often have a preemptive character. There are also opinions that the increase in the quantity of application of this approach under the Obama administration was caused by the effort to avoid the complications the previous Bush administration had with the status of people suspected of hostile activities. These individuals, mostly captured in operations in Afghanistan, were detained at the base in Guantanamo without enjoying the protection resulting from the international conventions and, in a number of cases, also without any charges, thus, their status outside of the law raised strong criticism. Physical liquidation of similar persons during special operations using drones helps avoid similar controversies, albeit at the cost of loosing the possibility of intelligence exploitations of such individuals. On the other hand, the program of targeted eliminating of enemy persons raises new controversies. UAVs, according to critical voices, reduce the threshold of political sensitivity toward using force, as piloted machines have never been used to such an extent for intelligence controlled extrajudicial neutralization of individuals on the territory which the operating state was not in a state of war with. Flexible deployment, efficiency, absence of human crew as well as the low cost of drones may 
reduce barriers for the political actors in deciding whether or not to use violence and make it easier to authorise problematic kinetic operations. The employed modern technology, therefore, does not represent a neutral tool in terms of values in this case, rather, it creates structural conditions for the action of human actors itself. From the point of view of the critics, drones also allow the elites of leadership to wage war almost constantly without significant costs and without more profound interest in the matter or resistance from the public, thus becoming a tool of unethical and immoral policy [7].

\section{Controversies}

There is also a problematic cultural and societal dimension of the use of drones. This is obvious namely in the conflicts that the West conducts in an entirely different cultural environment. Even though drones are not autonomous robotic systems and in practical terms there is not a big difference whether the target object has been hit by a remote-controlled drone, piloted aircraft or artillery, from the point of view of a contemporary adversary and regional population it is not perceived this way. Present day drones are often viewed as an almost robotic weapon which, despite its technological sophistication, represents a symbol of cowardice and decline of the West. This is especially due to the perceived reluctance to risk or engage the lives of their own soldiers for the values that the West is trying to import into the local environment. An unwanted contrast arises between the dedicated combatants martyrs on the one hand and the murderous robotic weapons these heroes have to resist, engaged in an uneven fight. The technical superiority already ceases to be seen as a manifestation of power and the strength of the opponent, as it was the case in the recent past, instead, it becomes a symptom of their weakness. The military inferiority of insurgent or terrorist groups can turn into an ideological advantage and the prospective struggle of values may not resound favourably for the West. The population in the areas of drone operations facing the collateral damage caused by their strikes is not a suitable material for winning the hearts and minds. A number of expert treatments argue that despite their deadly efficiency, drones produce more enemies than they manage to eliminate. Therefore, the debate over the current use of armed drones can result, in some cases, in the reluctance or refusal to use these resources by the political actors, if they are subjected to strong social disfavour as a result. An example can be seen in the current controversy about the introduction of armed drones into the equipment of the French army. This trend is not welcome by the public opinion under the influence of leftleaning intellectuals, regardless of the fact that from the practical point of view there is no difference between using drone and any other standard means of combat. In addition, unlike the American operators, the French ones are still active in situ, that is directly in the area of deployment, thus, we cannot speak of the unethical absence of personal risk. The current debate includes also differing opinions claiming that combat drones are entirely legal and legitimate weapons, which are, contrary to their negative image and owing to their high accuracy, more humane than other contemporary and socially accepted combat weapon systems. Along with the negative perception of the armed drones, the concept of drones as operator risk free weapons can be also challenged. The drone operators, based on several studies, suffer from comparable psychological stress as soldiers in the field, while it is more difficult for them to overcome this stress due to their physical isolation from the area of deployment. Moreover, these operators are only a part of a wider complex, as the deployment of drones is inextricably connected to the activities of the special forces in the target area and the drones are in some cases directly piloted by them. 
Furthermore, it is not possible to rule out the risk of attacking one's own or allied troops while there is also a concentration of the opponent's effort toward people or objects associated with the deployment of drones. The suicide attack from 2009 against the US military base in eastern Afghanistan, which resulted in the death of eight CIA agents, was primarily motivated by the fact that the rebels identified these people as collecting information for targeted drone attacks. French soldiers in Afghanistan had a similar experience when their base was exposed to a series of attacks by the insurgents after commencing the exploratory activities of their Harfang drone [8].

The risk factor of deployment can also have a technical nature, in other words the opponent's drone can be seized and potentially used or directly applied against their own forces or the civilian population. This option cannot be entirely excluded, as it is illustrated by the case of the Iranian capturing of the US drone Sentinel, which probably resulted in the Iranian success in decoding the data of a drone of the same type active in the Afghan Kandahar. A similar incident was taking control of the US drone by the Iraqi Shiite rebels in 2010 using a commercially available application called SkyGrabber worth only EUR 18 . We can also mention the penetration of an outsider person into the system of the research drone used by NASA in 2015, so the concerns about the potential enemy takeover of drones in the future are not totally unjustified. In combination with the use of commercial and generally available drones, there is a significant increase in the risk that, using open source resources, an asymmetric adversary can also obtain effective and inexpensive means to strengthen their capacities and destructive potential [9].

\section{Conclusions}

Over the last few years, UAVs have significantly influenced the way of waging wars and counter-insurgency operations, while their potential, despite the dynamic development of this system, is still far from exhausted. Developed armed forces increasingly use these resources to replace the former piloted air technology in the field of reconnaissance activities and a similar trend is to be expected also in the case of armed combat resources. Today, armed drones are used primarily in the areas of targeted elimination of enemy combatants. Their more extensive military use in conventional fighting, at least at a tactical level, may be expected in the near future. The present and prospective use of military drones is the subject of controversy and criticism, often associated with the concerns that this trend will result in significant robotization of the battlefield and the associated adverse effects. These effects include possible misuse of the unmanned weapon systems, based on their expected availability, or employing an unethical, dehumanized way of combat, which will, furthermore, generate new enemies and their asymmetric reaction. Still, it is more than likely that confronted with the efficiency of drones and similar systems all of these concerns and assumptions will be outweighed by the political and military arguments and the logical effort to take advantage of the economic benefits associated with their use, while minimizing the potential of human losses on the side of their user.

\section{References}

[1] FUČÍK, Jakub, Moderní technologie a ozbrojený konflikt. In Vybrané trendy vývoje bezpečnostního prostředí a možné implikace pro ozbrojené síly. Brno, Univerzita obrany, 2017, p. 49. 
[2] ZAJEC, Olivier. La prolifération robotique dans le monde. In Défense et Sécurité Internationale. Numéro Hors-Série No. 10, 2010, p. 97.

[3] TISSERON, Antonin, Robotic and Future Wars. In Robots on the Battlefield. Contemporary Issues and Implications for the Future. Kansas, Combat Studies Institute Press US Army, 2014, p. 33.

[4] MALIS, Christian. Nouvelles extrapolations. Robotisation et revolution dans les affaires militaires. La guerre robotisée. Paris, Economica, 2012. p. 51.

[5] DE BOISBOISSEL, Gérard. Une réponse à la lettre ouverte sur l'interdictiondes Arbes autonomes. In Défense et Sécurité Internationale. No. 120, pp. 33-36, 2015.

[6] POWERS, Edgar, W. Developing and Integrating Unmanned Systems for Military Operations. In Robots on the Battlefield. Contemporary Issues and Implications for the Future. Kansas, Combat Studies Institute Press US Army, 2014, p. 195.

[7] GUSTERSON, Hugh. Drone: Remote Control Warfare. Washington, MIT Press, 2016, p. 51.

[8] VILMER JEANGÈNE, Jean-Baptiste. Drones armés et systèmes d'armes létaux autonomes: des enjeux différents. In Drones et killer robots. Faut-il les interdire? Rennes, Presses Universitaires de Rennes, 2015, pp. 94-96.

[9] FRANK, Libor, STOJAR, Richard. Changes in Armed Forces and their Significance for the Regular Armed Forces. Proceedings of $18^{\text {th }}$ International Scientific Conference KBO, pp. 142-145, Sibiu, Romania, June, 2012.

ACKNOWLEDGEMENT - The work presented in this paper has been supported by the Ministry of Defence of the Czech Republic (Research Project "STRATAL" No. 907930101023). 